\title{
DISCLAIMER
}

Tnis report was prepared as an account of work sponsored by an agency of the United States Government. Neither the United States Government nor any agency thereof, nor any of their employees, makes any warranty, express or implied. or assumes any legal liability or responsibility for the accuracy, coripleieness, or usefulness of any information, apparatus, pruciuct, or process disclosed, or tepresents that its use would not infringe privately owned rights. Reference herein to any specific commercial product, process, or service by trads name, trademark, manufacturer, of otherwise does not necessarily constitute or imply its endorsement, recommendation, of lavering by the United Slales Government or any agency thereof. The views and opinions of authoes expressed herein di: not necessarily state or reflest those of the United States Government of any agency thereof.

\section{LOSS OF BEAM IONS TO THE INSIDE OF THE \\ PDX TOKAMAK DURING THE FISHBONE INSTABILITY}

PPPL- -2398

DE87 005630

W.W. HEIDBRINK, P. BEIERSDORFER

\author{
Plasma Physics Laboratory, \\ Princeton University, \\ Princeton, New Jersey \\ United States of America
}

\begin{abstract}
Lising data from two vertical charge-exchange detectors on the Poloidal Divertor Fxperiment (PDX), we have identified a set of conditions for which loss of beam ions inward in major radius is observed during the fishbone instability. Previously, it was reported that beam jons were lost only to the outside of the PDX tokamak.
\end{abstract}


In high $\beta_{T} q$ discharges with near-perpendicular neutral beam injection in PDX, an MHD instability called the fishbone instability ejected beam jons from the plasma [1]. Theoretical studies by. White et al. [2] found that rotating MHD modes similar to those observed in the experiment resonate with the toroidal precession of the beam-ion orbits. resulting in the loss of nany of the jujected beam ions. The mode resonance was predicted to produce a beacon of outwardly exiting bean particles correlated with the mode rotation [2]. Studies of the charge-exchange efflux with toroidally displaced detectors found the predicted $n=1$ modulation of the beam-ion loss $\{3 j$. The mode-particle resonance theory also correctly predicted experimental observations that the beam-ion loss scales lineariy with the amplitude of the mode 4 . The loss of non-resonant fusion products also could be explained using White's fisbbone model [5!. Further support for the model was given in Ref. 3. Where measurements with two vertically viewing neutral-particle analyzers indicated that beam iens were lost to the out side of the plosma but not to the inside.

In this letter. dat a from the inner vertical clarge-exchange detector (IDE) of Ref. [3] are presented that indicate that $50 \mathrm{keV}$ beam ions were lost to the inside of the PDX tokamak during the fishbone instability when the ions measured by IDE were on confined orbits.

Fig. 1 shows bursts of charge-exchange flux on IDE that correlate with bursts of fishbone MHD actjvity. In this discharge, the plasma underwent a transition into the High-mode [ 6 ] at 480 msec. Prior to the transition, large $(\geq 10 \%)$ variations in $H_{\kappa}$ enlission were not observed but, after the transition. sudden changes in neutral dessity associated with Edge Relaxation Phenomena (ERP) [i] correlate with charge-exchange bursts and fishbones. Conceivably, variations sil neutral density might acconnt for the bursts on IDE in the High-node but in the Low-mode the charge-exchauge bursts are almost certainly due to an increase in the number of fast ions in the IDE sightline. From the relatively gradual decay of the MHD bursts $(\sim 1 \mathrm{msec})$, the possibility that sawteeth were coincident with the fishbones can be excluded $[4,8]$, so the bursts are not dite to the iransport of the fast jons at sawteeth $[9$. Since the IDE sightline skins the inner radius of the plasma. these bursts indicate that fishbones transport be am ions inward in major radius as well as outward.

Usually the signal-to-noise ratio on IDE was inadequate to asrertain if the chargeexchange flux was modulated by the fishbone oscillations (as it was on the outer edge of the plasma [1.3j]. Fig. 2 shows one of the few events where internal structure seems to be present. This burst was syuchronous with a large fis]bone (fractional change in geutron emission $\Delta I_{n} / I_{n}=25 \%$ ) in a discharge with relatively large neutral density 
$\left(P_{b}=4 . i M W\right)$. It is estinrated that the peak signal level corresponds to less than one hundred counts at the IDE chamneltron detector, so even in this case errors assuciated with counting statistics are appreciable. A peak in the Fourier spectrum occurs near the frequency of peak amplitude of the Mirnov oscillations. suggesting that the spikes are due to beam-ion motion induced by the mode.

A further indication that ions were lost to the inside of the tokamak is that the change in Aux at a fishbone scales approximately linearly with the severity of the fishbone (Fig. 3). The qulantity $\Delta I_{n} / I_{n}$ in Fig. 3 is approximately the fraction of energetic ions lost at the fishbone event [4]. Fig. 3 shows that the flux depends much more strongly on $\Delta I_{n} / I_{n}$ than on the existence of a coincident ERP instability.

All of the above data are for neutrals with energy $E$ approximately equal to the neut ral beam injection energy $E_{i n j}$ and $I_{p} \gtrsim 350 \mathrm{kA}$. For energies well above $E_{i n j}$ ( $E$ $E_{i n j} \gtrsim 10 \mathrm{keV}$ ) or slightly below $E_{i n,}\left(E-E_{2 n j} \approx-3 \mathrm{keV}\right)$. bursts of beam jons were not clearly olsserved on IDE unless an ERP or sawtooth instability was coincident with the fishbone (Fig. 4). For $E-E_{i n j} \lesssim-10 \mathrm{keV}$, a combined fishbone and ERP sonetimes increased the flux an order of magnitude relative to the flux at eit her a fishbone or an ERP alone. It appers that ions with $E=25-3.5 \mathrm{keV}$ were not moved into the IDE sight line unless the fishbone instability was assisted ly transport from another instability.

Bursts on IDE during the fishbone instability were not observed unless the plasma current was sufficiently large to confine beam ious in the IDE sightline (Fig. 5). For denterons with energy $E=45 \mathrm{keV}$, most of the ions in the IDE siglttline hit vacuum vessel hardware when the plasma current was below $I_{p} \leqslant 275 \mathrm{kA}$. The corresponding cutoff for the outer detector (ODE) at $45 \mathrm{keV}$ was $I_{p} \approx 225 \mathrm{kA}$. PDX rarely operated below $225 \mathrm{kA}$, however, so a reduction in the amplitude of the burst at low plasma current was not observed on ODE for $E \leqslant E_{i n j}$. In fact, ODE measured bursts during the fishbone instability even if the detected ions were on unconfined orbits: for example, large bursts were observed with ODE at $E=80 \mathrm{keV}$ at $I_{P} \simeq 225 \mathrm{kA}$.

In conclusion. for $I_{p} \gtrsim 350 \mathrm{kA}$ and $E \gtrsim E_{\text {in }}$. fast ions were lost to the inside of the tokamak at the fishbone instability. These losses still were two orders of magnitude less than the losses to the outside of the tokamak observed on ODE. however. Detailed Monte Carlo simulations of fishbones predict [10. that some ions should nove inward in major radius due to a combination of mode-particle pumping '2] and classical Coulomb scat tering. Thus, the observation of some transport to the inside of the tokanak is not inconsistent with either mode-particle pumping theory '2: or with the major conclusions of the PDX paper that first reported results from IDE [ 3 ; 


\section{ACKNOWLEDGEMENTS}

We thank R. Fonck. R. Goldst on. R. Fiaita, H. Kugel. K. McGuire, and J. Strachan for data used in this study and F. Doughty and T. Locke for assistance in forming a database. Helpful suggestions by J. Strachan are gratefully acknowledged. The PDX project was supported by L.S. Department of Energy Contract No. DE-AC02-76-CHO-3073 and cue of us (P.B.) was supported by the Fannie and Jotur Hertz Foundation.

\section{REFERENCES}

il MicGliRE, K., GOLDSTON, R., BELL, M., BITTER, M., BOL, K. et ai., Phys. Rev. Lett. 50 (1983) 891.

[2] WHITE, R.B., GOLDSTON, R.J, McGLIRE, K̈., BOOZER, A.H., MONTICELLO, D.A., PARK, W., Plyvs. Fluids 26 (1983) 2958.

3! BEIERSDORFER. P., KAITA, R., GOLDSTON, R.J.. Nucl. Fusion 24 (1984) 48 \%.

iA? STRACHAN. J.D. GREK, B., HEIDBRINK, W., JOHNSON, D., KAYE, S. tt al., Nucl. Fusion 25 (1985) 863.

5! HEIDBRINK. W.W., HAY. R.. STRACHAN, J.D.. Phys. Rev. Lett. 53 (1984) 1905.

(6) NAGNER. F.. et al.. Phys. Rev. Lett. 49 (1982) 1408.

: McGílRE. K. et al., in Plasma Physics and Controlled Nuclear Fusion Restarch (Proc. 1Uth Int. Conf., London, 1984), Vol. 1, IAEA, Vjenna (1985) 117.

8) BlCHENALER. D., Ph.D. Thesis, Princeton University, 198.

9. GOLDSTOK. R.J., KAITA, R., BEIERSDORFER, P., GAMMEL, G.. HERNDON. D.L., et al., Princeton Plasma Physics Laboratory Report No. PPPL-2359 (1986).

10] HAY, R.G., private communication (1985). 


\section{Figure Captions}

Fig. 1 (a) Time evolution of $\dot{B}_{\dot{b}} . I D E$ flux at $E=4.5 \mathrm{keV}$, and $H_{\alpha}$ emission from the $P D X$ dome in a discharge that underwent a transition into the High-mode at 480 msec. $P_{b}=2.5 \mathrm{MH}: E_{i n j}=43.9 \mathrm{kel}: \tilde{n}_{t}=1.6 \times 10^{13} \mathrm{~cm}^{-3}$ (at $\left.480 \mathrm{msec}\right): I_{p}=360 \mathrm{kA}:$ $B_{i}=1.7 T$. (b) Cross-correlation functions of $\dot{B}_{\theta}$ with IDE flux and IDE fux with the $H_{c}$ signal during the Low-mode $(100-170 \mathrm{msec})$. The IDE signal correlates strongly with the Minnor signal but less strongly with the $H_{\alpha}$ emission. The correlation or IDE flux with $H_{a}$ enission from the midplaje is even weaker.

Fig. 2 (a) Time evolution of the IDE signal ( $E=40 \mathrm{kel}$ ) through a large fishbone $\left(\Delta I_{n} / I_{n}=25 \%\right)$ in a plasma with relatively large neutral density. $P_{b}=4.7 \mathrm{MW}: I_{p}=$ $320 \mathrm{kA}: B_{1}=17.8 \mathrm{kG} ; \beta=1.1 \%$. (b) Fast Fourier 1ransform (amplitude) of the IDE signal in (a). The lines indicate the range of frequencies over which large amplitude oscillations were abserved on a Mirnov coil. The peak in the Fast Fourier transform amplitude at the fisfibone frequency is raughly ten times larger than the amplitude which results from analyzing IDE signals without a concurrent fishbone instability:

Fig. 3 Change in flux averaged over a fishbone burst versus the drop in the neutron emission, $\Delta I_{r} / I_{n} . E-E_{i \pi j}=3-8 \mathrm{kel} ; I_{p} \therefore 345 \mathrm{kA}$. The error bars are estimates of the effect of noise on the measurements.

Fig. 4 Flux ateraged over a fishbone burst versus energy for moderate amplitude fishbones $\left(\lambda I_{n} ; I_{n}=5 \%\right) . I_{p}>345 \mathrm{kA}$. The hatched region is the flux observed in the absence of tishbones: statistically significant bursts lie above this hatched region. Below $\sim 10^{-2}$. the noise is comparable to the signal. The solid points indicate that a spike in the $H_{o}$ emission. (an ERP) was coincident with the fishbone.

Fig. 5 ('hange in fux averaged over a fishbone burst versus plasma current for moderate amplitude fisbbones $\left(\Delta I_{n} / I_{n} \therefore 5 \%\right) . E-E_{i n j}=3-8 \mathrm{kel}$. The line indicates the approximate current level where orbits of $50 \mathrm{keV}$ deuterons in the IDE sightline become confined. 


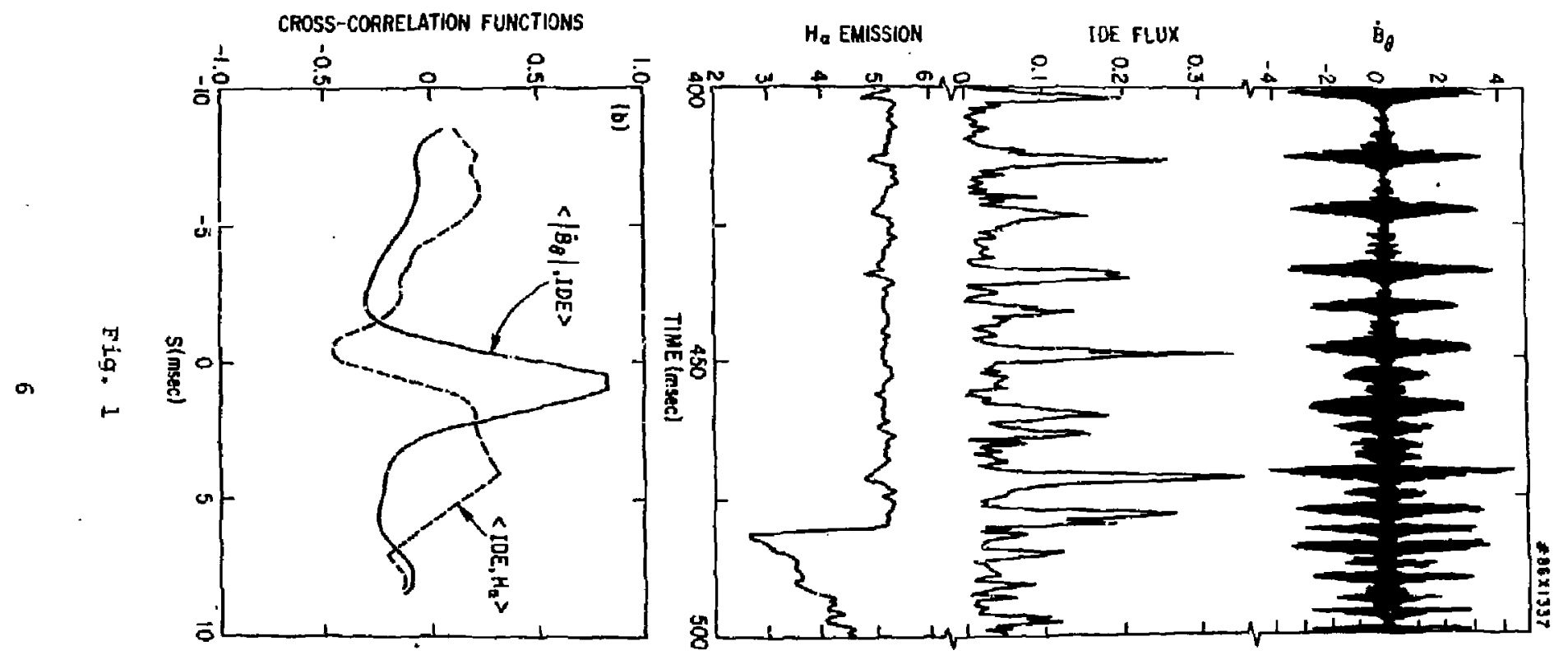



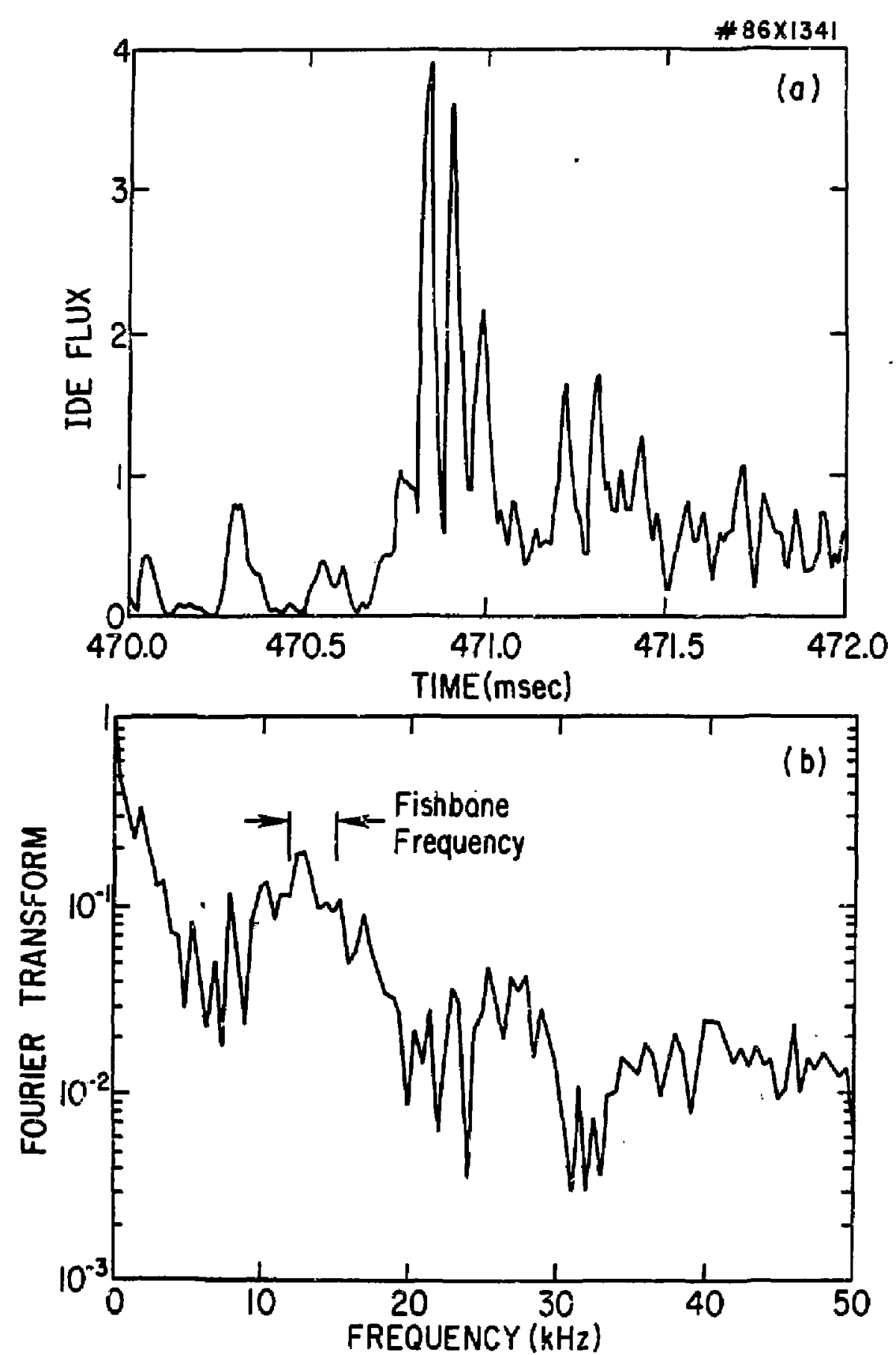

Fig. 2 


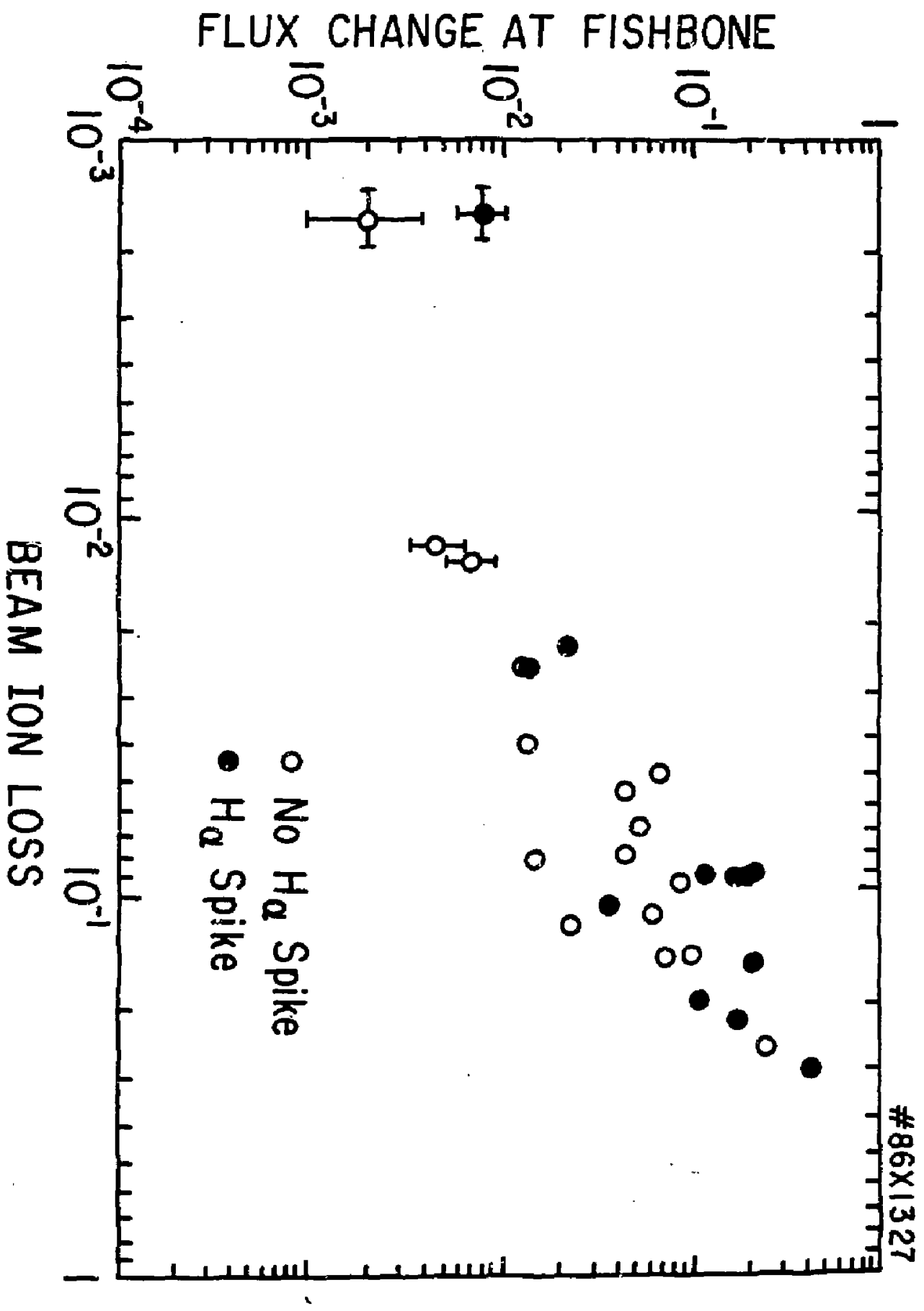




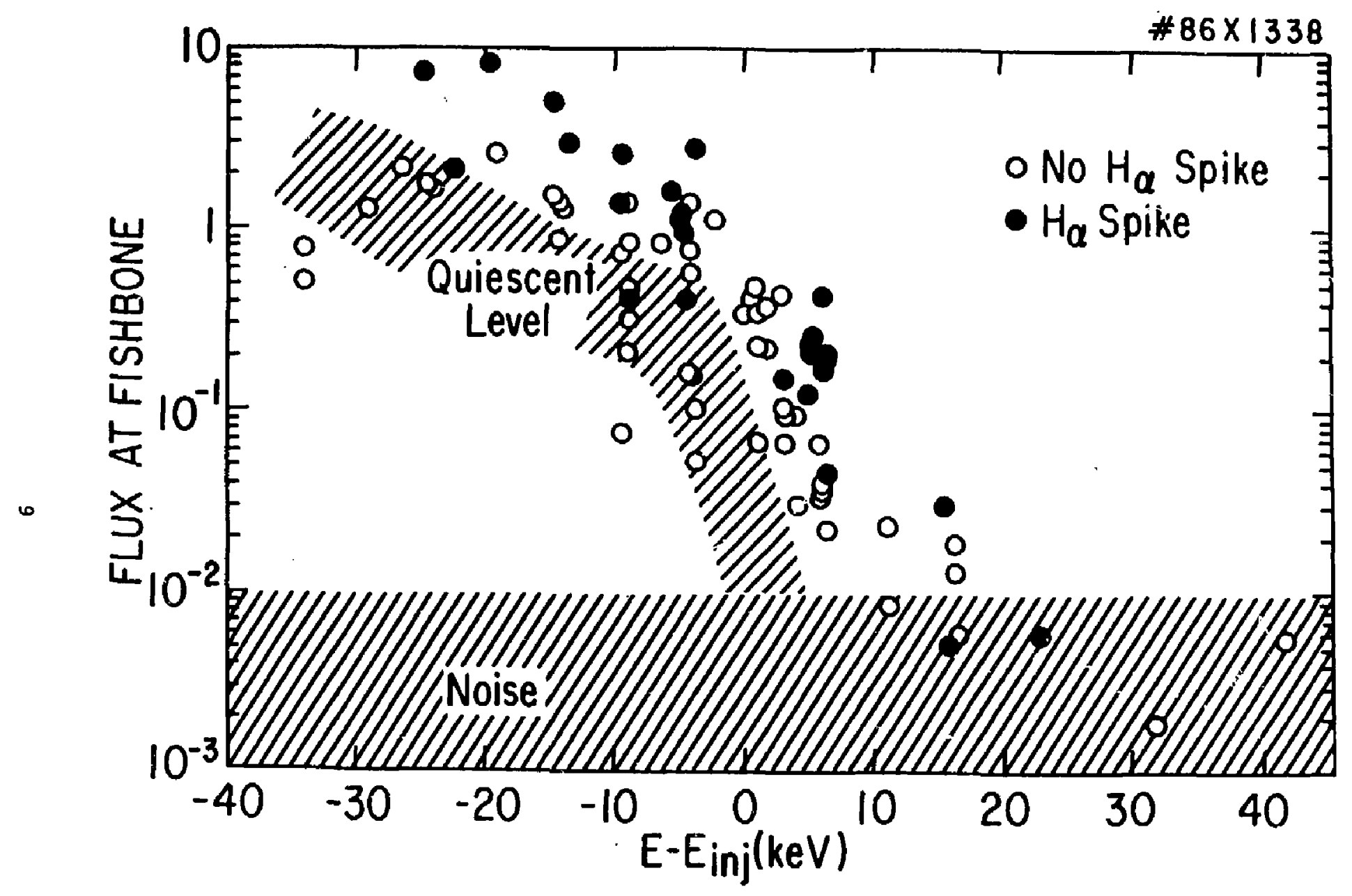




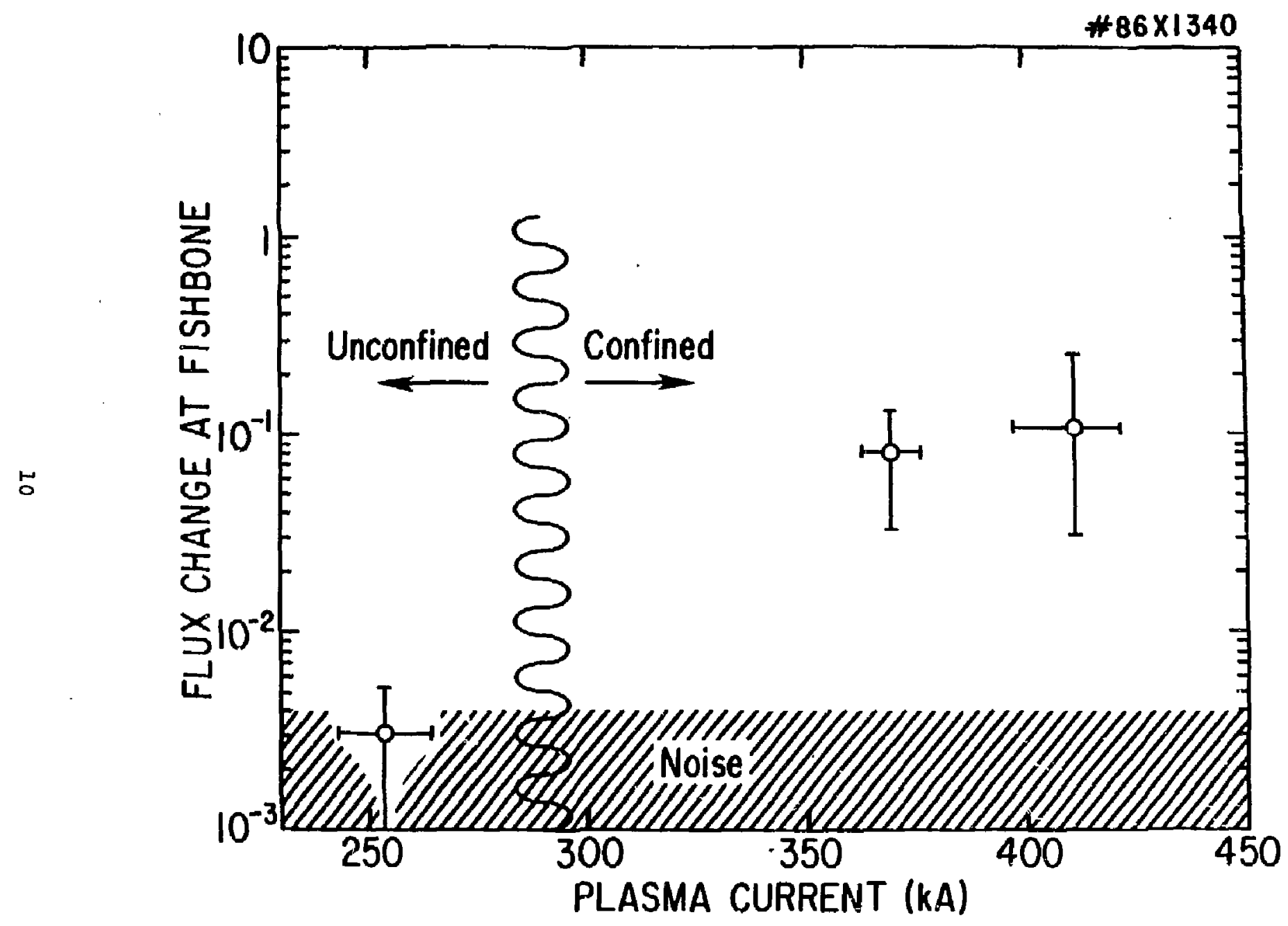

Fig. 5 
Plasma Res Lab, Austra Nat'l Unly, Australia

Dr. Frank J. Paolonl. UnIV or Wol longong, AUSTRALIA

Prof. $1, R$, Jones. Fi inders Univ,. AUSTaAlia

Prot. M,H, Broman, Uniy Sydney, AUSTRALIA

Prot. F. Cap, Inst Thes Phys, AUSTRIA

$M$, Goossans, Astronomlsch Instituut, BELliflu

Prof, R. Bovelque, Laboratorlum voor Natuli-kunde, JELGIUM

Dr. D. Palumbo, Dg XII Fuslon Prog, BELGILM

Ecole Royale Militalre, Lab de Phys Plosmes, BEl.'sluM

Dr. P.H. Sakanaka, UnIV Estadual, aRAZIL

LIb. Doc. Div.. Instituto de Pesquisas Espaciala, BRAZI

Dr. C.R. James, Unlv of Alborta, CAMAOA

Prof. J. Tolchmann, Univ of Montred, CANAOA

Dr. H.M. Skarsgard, Unlv of Saskatchearan, CANADA

Prof, S,R, Sreanlvasan, Universtty of Calcory, CANAOA

Prof. Tudor $W$. Johnston, INRS-Energla, CANiNDA

Dr. Hennes Barnard, Univ British Columbla, CAMAOA

Dr. M.P. Bachynskl, MPB Tochnologles, Inc., CANADA

Chalk RIver, Nucl Lab, CANADA

Zhengwu LI. SW Inst Physles, CHINA

Library. Tsing Hua Univarsity. CHINA

LIbrarlan, Institute of Physles, CHIMA

Inst Plasm Phys, Academia Sinlco, CHIN

Dr. Peter Lukas, Komenskeho Linlv, GECHOSLOVAKIA

The Librarlan, Culnam Laboratory, ENGLAND

Prof. Schatzman, Observatolro de NIce, FRANCE

J. Radet, CENGPS, FRAKCE.

JET Reading Room, JET Jolnt Undertaking, ENGLAND

AM Oupas LIbrary, AM Dupas LIbrary, FRAMCE

Dr. Tom Mual, Acadony Jibllograptic, HONG KONG

Preprint Library, Cent fies Inst Phys, HUNGARY

Dr. R,K. Chhojlanl, Vikrom Unlv. INDiA

Dr. B. Oasgupta, Saha Inst, InolA

Dr. P. Kaw, Physlcal Resoarch Lab, INDIA

Or. Phlllip Rosunau, I sroel Inst Tech, ISRAEL

Prof. S. Cuporman, Tel Aviv Unlversity, ISRAEL

Prof. G. Rostagnl, Unly DI Padova, ITALY

Llorarlan, Intid Ctr Theo Phys, ITALY

Miss CIerla De Palo, Assoc EURATOM-ENEA, ITALY

BIblloteca, del CNR ELAATOM, ITALY

Dr. H. Yanato, Toshlba Res \& Dev, JAPAM

DIrec. Dept. Lg. Tokanak Dev. JAERI, JAPAN

Prof. Nobuyukl inoue, Unlvarsity of Tokyo, JAPAN

Research info Center, Nagoys Univarsity, JAPAN

Prof. Krojt Nishlkawa, UnIv of Hitoshima, JAPAN

Prof. SIgaru Morl, JAERI, JAPAN

Prot, S, Tanakg, Kyoto UnIvarsity. JAPAN

LIbrary, Kyoto University, JAPAN

Prot. I chl ro Kawakaml, Ninon UnIV, JAPAN

Prot. Satoshi Itoh, Kyushu University, JAPAN

Dr, 0.1. Chol, Adv, Inst Sel \& iech, KOREA

Tech Into Division, KAERI, KOREA
Bibllatheek, Fom-inst Voor Plasma, NETHERLAND's

Prot, B.S. LIlay. Universtty of Halkato, NEW ZEALANO

Prot, J.A.G. Cánal, Inst Superior Tacr, FORTUGAL

Or. Octavian Patrus, ALI CLeA IInivarsity, ROHANIA

Prof. H.A. Helloerg, Unlversity of Natal, 50 AFRICin

Dr. Johan de VIlllers, Plasma Physlcs, Nucor, SO AFriCA

Fusio: Olv, Llaracy, dER, SPAkN

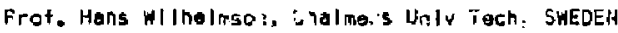

Or. Lennert STent $\because$, an I verstity of UMEA, SWEDEN

LIbrary, Royal Inst Tou 1, ShEt:EN

Centra de Recharchesen, Ecola Dolytech red, SwItzerland

Dr. Y,T, Tolok, Kharkav Phyg Tach Ins, USSR

'Jr. D,D. Ryura', SI berlan Acad Scl, USSR

Dr. G,A. EIlscev, Kurchatov Instltuta, USSR

Dr. V.A. Glukhith, Inst Eloctro-Physlcal, USSR

Instituta Gon. Physlas, USSR

Prof. T,J,M. Boyd, Unir calisge $N$ Walos, WALES

Dr. K. Senindtar, Rune Unl varsltat, w. GERMANY

ASOEX Roading Rm, IPPMax-Planek-lnstltut fü

Plasmaphyslk, F.R.G.

Nuctear Res Estab, Julleh Lto, GE, GRMANY

LIbrarlan, MaxPlanck Instlitut, W. GEPHANY

Blpllathek, Inst Plasmatorsehung. W. GERMANY

Prat, R,K, Janev, Inst Phys, YugosLAVIA 